\title{
Potencial da energia solar fotovoltaica no Semiárido nordestino
}

\section{Potential of photovoltaic solar energy in the northeastern semi-arid region}

\author{
Hermes Alves de Almeida ${ }^{1 *}$, Ednaldo de Ceita Vicente de Almeida ${ }^{1}$
}

\begin{abstract}
RESUMO
A questão energética mundial constitui um dos grandes desafios atuais e, ao mesmo tempo, gera grandes preocupações ambientais, na buscar fontes alternativas de energia que não degrade o meio ambiente. Diante disto, procurou-se quantificar o potencial de energia solar fotovoltaica no Semiárido nordestino, sendo essas determinações os objetivos principais. Foram utilizados dados mensais e anuais de irradiância solar global e de energia solar fotovoltaica, disponibilizados em sites do Instituto Nacional de Meteorologia, do Balanço Nacional Energético, do Ministério de Minas e Energia e outros. Os dados foram analisados, utilizando-se critérios da estatística descritiva, com cálculos de medidas de tendência central e dispersão, elaboração de figuras e tabelas pela planilha Excel. Os principais resultados indicaram elevada disponibilidade e regularidade de irradiância solar e, consequentemente, de conversão em energia fotovoltaica. A Paraíba é o estado do Nordeste com maior evolução temporal na capacidade instalada do sistema fotovoltaico e, portanto, uma fonte promissora para complementar a matriz energética nacional.
\end{abstract}

Palavras-chave: energia; irradiância solar; energia renovável; energia fotovoltaica.

\section{ABSTRACT}

The global energy issue is one of the great current challenges and, at the same time, generates great environmental concerns, in the search for alternative sources of energy that do not degrade the environment. In view of this, an attempt was made to quantify the potential of photovoltaic solar energy in the Northeastern semi-arid region, with these determinations being the main objectives. Monthly and annual data on global solar irradiance and photovoltaic solar energy were used, available on websites of the National Institute of Meteorology, the National Energy Balance, the Ministry of Mines and Energy and others. Data were analyzed using criteria of descriptive statistics, with calculations of measures of central tendency and dispersion, elaboration of figures and tables by Excel spreadsheet. The main results indicated high availability and regularity of solar irradiance and, consequently, of conversion to photovoltaic energy. Paraiba is the Northeastern state with the greatest temporal evolution in the installed capacity of the photovoltaic and, therefore, a promising source to complement the national energy matrix.

Keywords: energy; solar irradiance; renewable energy; photovoltaic.

\footnotetext{
${ }^{1}$ Universidade Estadual da Paraíba (UEPB), Campina Grande, PB

*E-mail: hermes_almeida@uol.com.br. Bolsista CNPq pós-doutorado Sênior
} 


\section{INTRODUÇÃO}

A questão energética constitui um dos grandes desafios atuais e, ao mesmo tempo, gera grandes preocupações ambientais, na buscar fontes alternativas de energia que não degrade o meio ambiente e possibilite o desenvolvimento econômico e social.

A relação do homem com a natureza e com o advento da sustentabilidade, o uso dos recursos naturais tem mostrado risco ao meio ambiente, concorrendo para o início das ações de políticas que incluem o desenvolvimento sustentável.

Muita energia vem do Sol para a Terra, mas pouco é aproveitado. Uma pequena parte é incorporada nos vegetais através da fotossíntese e serve para sustentar toda a cadeia alimentar do planeta. Ao longo do tempo, a matéria orgânica se acumulou no subsolo terrestre, formando as chamadas fontes fósseis de energia: petróleo, carvão mineral, gás natural, xisto betuminoso e outros (GOLDEMBERG e LUCON, 2007).

A demanda crescente por energia para o desenvolvimento das atividades econômica, industrial e humana desencadeou o consumo de fontes de energia, especialmente, as não renováveis, como as oriundas de combustíveis fósseis. No Brasil, o modelo elétrico brasileiro, tem a sua matriz energética, majoritariamente, gerada nas usinas hidroelétricas, consideradas uma das fontes mais limpas e renováveis do mundo (SUZIGAN, 2015).

O conceito mais recente de desenvolvimento sustentável incorpora a necessidade de adoção de parâmetros de sustentabilidade tendo em conta o risco ambiental (Romeiro, 2012), em virtude da intensificação da crise do petróleo e a defesa do meio ambiente para as atuais e futuras gerações.

A energia solar fotovoltaica é obtida através do efeito fotovoltaico, que consiste na conversão direta da irradiância solar em energia elétrica, sendo considerada uma alternativa promissora para expansão da oferta de energia elétrica com baixo impacto ambiental (GASPARIN et al., 2021).

O Sertão do Nordeste brasileiro tem características geográficas e climáticas que favorecem a geração de energia solar fotovoltaica (Silva et al., 2016), embora ainda pouca utilizada, principalmente, nas áreas rurais, onde não se tem acesso a rede de distribuição de energia elétrica.

A disponibilidade da irradiância solar no Brasil é bem maior que em outros países do hemisfério norte, embora tenha menor capacidade instalada de energia solar fotovoltaica. Comparando-se a menor incidência de irradiância solar, no estado de Santa Catarina, por exemplo, com valor próximo a 4,25 kWh/m²/d (Martins, Pereira e Abreu, 2007), constata-se, que é ainda superior ao maior da Alemanha (Simioni, 2017), mesmo recebendo 40\% menos (MOREIRA JÚNIOR e SOUZA, 2020). 
No Brasil, a principal fonte de geração de energia elétrica é a hidráulica (ANEEL, 2008) e, somente, a partir de 2012, a Resolução Normativa $n^{\circ} 482$ estabeleceu o marco inicial dos sistemas conectados à rede elétrica, com crescente uso da micro e mini geração de energia, com a maioria das conexões ligadas a rede elétrica residencial (ANEEL, 2017).

Dentre as fontes renováveis de energia, a solar fotovoltaica é uma das mais abundantes na superfície terrestre, além de ser uma das alternativas mais promissoras na composição da nova matriz energética mundial, esperada ser, até 2040, a fonte renovável de energia mais importante do planeta (VERMA, MIDTGARD e SATRE, 2011; BRITO et al., 2011).

Sanzio e Nascimento (2016) citaram que, em meados da década de 60, houvera avanços na tecnologia para conversão da energia solar em elétrica, por ser uma fonte limpa e de baixo impacto ambiental para a sua geração. $\mathrm{O}$ investimento na tecnologia solar foi massivo, mas a queda do preço do petróleo impediu que tecnologia solar fosse competitiva, o que fez a humanidade se tornar dependente de combustíveis fósseis (DIENSTMANN, 2009).

O uso de fontes renováveis de energia não é um assunto novo e a busca por novos tipos de energia limpa, renovável e sustentável cresce a cada ano e visa oferecer diferentes alternativas para o uso de energia que não degradem o meio ambiente.

Diante disto, procurou-se averiguar o potencial da energia solar fotovoltaica no Semiárido nordestino, sendo essas determinações os objetivos principais.

\section{MATERIAL E MÉTODOS}

O trabalho consistiu em quantificar o potencial da irradiância solar global, para conversão em energia fotovoltaica no Semiárido nordestino (Figura 1), utilizando-se os diversos recursos da Estatística Descritiva.

Figura 1. Croqui do mapa geográfico do Brasil, com destaques para o Semiárido nordestino.

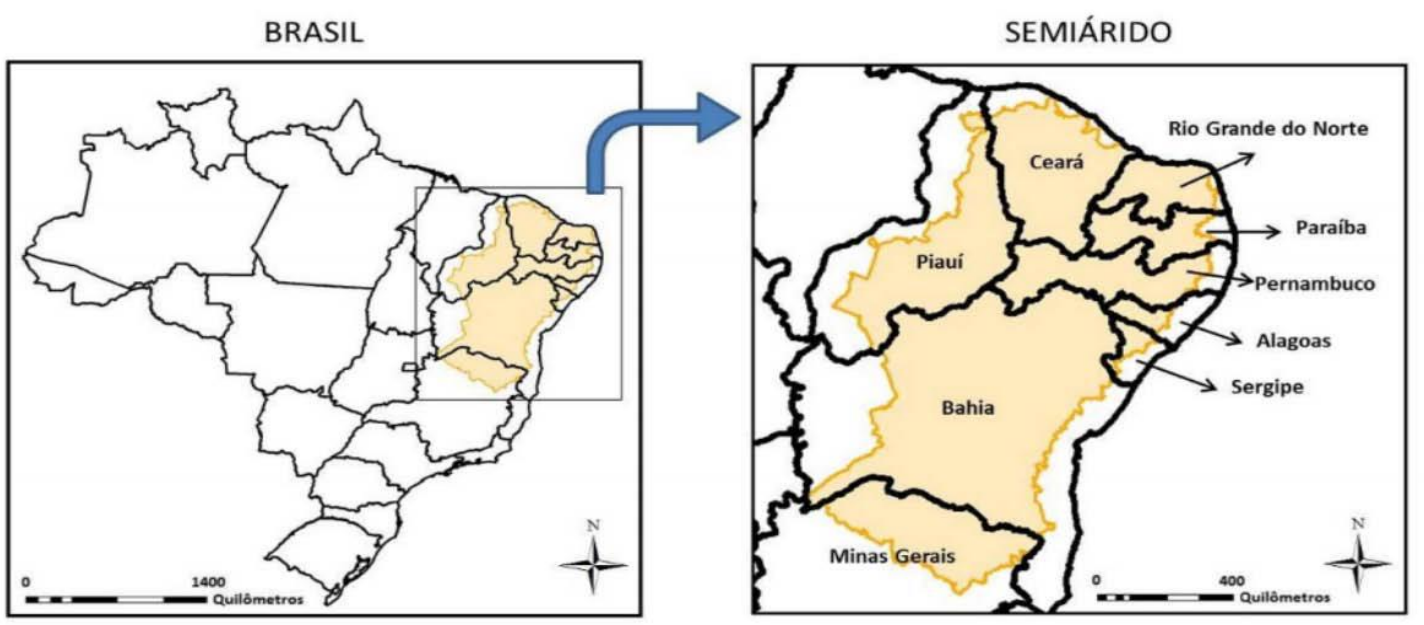

Fonte: Barbosa et al., (2017) 
Os dados de irradiância solar global e solar fotovoltaica foram extraídos diretamente dos relatórios, artigos científicos e/ou disponibilizados nos sites do: Instituto Nacional de Meteorologia (INMET- https://portal.inmet.gov.br/), do Ministério de Minas e Energia (MMEhttps://www.gov.br/mme/pt-br), da Agência Nacional de Energia Elétrica (ANEELhttps://www.aneel.gov.br/), da Empresa de Pesquisa Energética (EPEhttps://www.epe.gov.br/pt/publicacoes-dados-abertos/publicacoes), da Associação Brasileira de Energia Solar Fotovoltaica (ABSOLAR- http://www.absolar.org.br/) e de outros órgãos.

Com os dados mensais e anuais foram calculadas as medidas de tendência central (média e mediana), percentuais e evolução temporal das diferentes fontes de energia nos anos de 2018 a 2019 e a potência instalada da matriz energética brasileira em operação, sendo confeccionados em formas de gráficos e mapas.

As médias mensais e diárias da irradiância solar do NE nos meses da primavera, verão e no trimestre mais chuvoso foram plotadas em gráficos, como também, a evolução temporal da irradiância solar no Nordeste, nos meses da primavera, verão e no trimestre mais chuvoso, do período de 2006 a 2016.

Adotando-se procedimentos semelhantes foram confeccionarão os gráficos, na forma de histograma de frequência, com análises comparativas entre as médias mensais de irradiância solar no Estado da Paraíba e as da Alemanha e evolução temporal da capacidade instalada para aproveitamento da energia solar em energia fotovoltaica no Brasil versus NE, com destaque para a Paraíba, Pernambuco e Rio Grande do Norte.

Os cálculos, análises e confecções de gráficos e tabelas forma feitas utilizando-se a planilha eletrônica Excel.

\section{RESULTADOS E DISCUSSÃO}

A importância da eletricidade para a sociedade é algo que existe desde as épocas mais primitivas. Para as sociedades atuais, a energia elétrica passa a ser ainda mais relevante, por que os hábitos fazem aumentar o seu uso.

O Brasil é, atualmente, uma referência mundial de fontes de energia renováveis, ou seja, de fontes naturais, com destaque para as energias: hidráulica, solar, eólica, etc.

A energia dita de sustentável é aquela que mantém um equilíbrio entre a produção e o consumo, ou seja, quando o consumo em quantidade e em velocidade não ultrapasse a capacidade da natureza em repô-la.

A ideia de energia limpa é associada à capacidade de poluição decorrente do seu uso, a que não polui, ou a que polui menos, quando comparada com a energia oriunda de combustíveis fósseis. 
A Figura 2 apresenta os percentuais de fonte energéticas mais utilizadas, mundialmente, para produção de energia elétrica.

Figura 2. Percentuais das principais fontes da matriz energética mundial, em 2002.

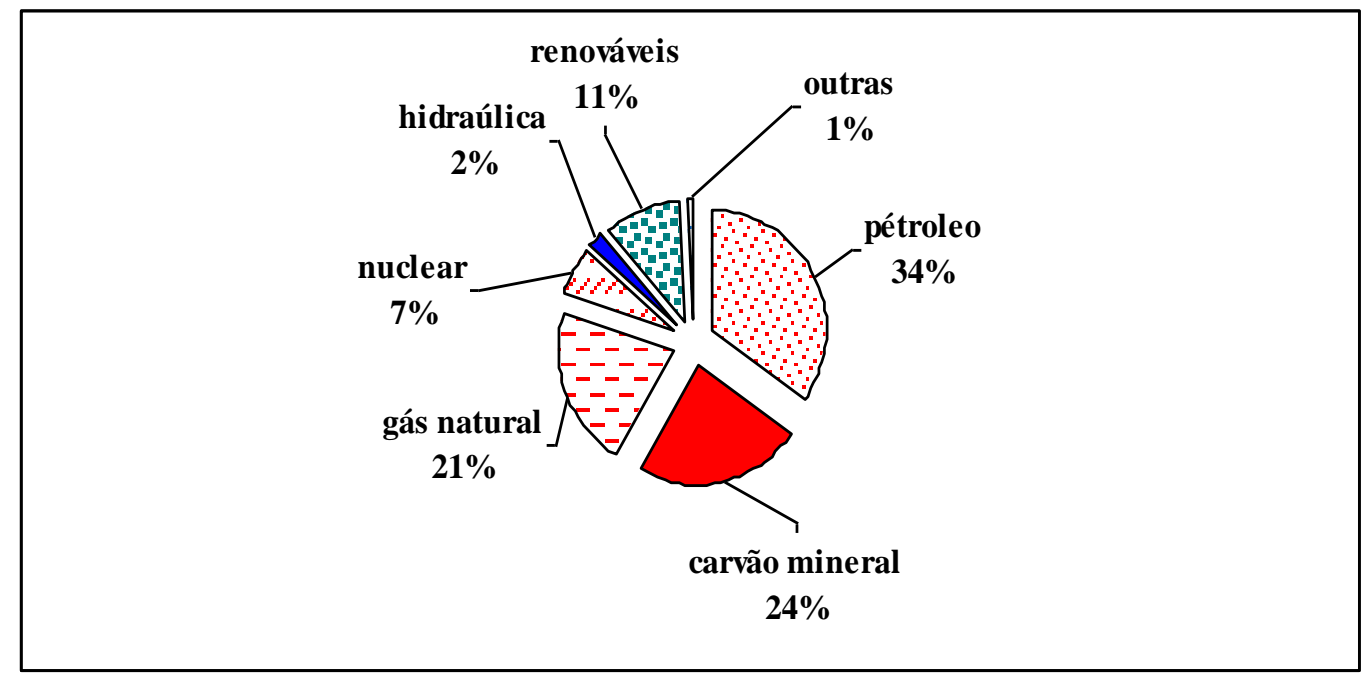

Fonte: https://educacao.uol.com.br/disciplinas/geografia/fontes/elaborado pelos autores.

Observa-se (Figura 2), que o petróleo, o carvão mineral e o gás natural representavam, em 2002, cerca de $80 \%$ da matriz energética mundial. O carvão mineral, por exemplo, é uma complexa e variada mistura de componentes orgânicos sólidos, fossilizados ao longo de milhões de anos.

No Brasil, até o final do século XIX, a atividade econômica era significativamente agrária e a participação da eletricidade, como fonte de energia era inexpressiva. A partir de 1920 e com o início da industrialização e a concentração da população em centros urbanos, a opção foi para a geração de energia elétrica através de usinas hidroelétricas, cuja evolução das diferentes fontes da matriz energética, em 2018 e 2019, é apresentada na Figura 3.

A predominância pela energia hidráulica no Brasil, pode até ser justificada pela abundância de água, algo em torno de 12 a 13 \% das águas doces disponíveis em todo o planeta Terra. Condições essas que corroboram com Abbud e Tancredi (2010) e outros; a maior disponibilidade de água, uma das suas maiores riquezas nacionais, potencializa a geração de energia elétrica renovável, através de usinas hidrelétricas.

Na realidade, o uso da energia hidráulica foi uma das primeiras formas de substituição do trabalho animal pelo mecânico, particularmente para bombeamento de água e moagem de grãos. 
Figura 3. Evolução das diferentes fontes de energia no Brasil

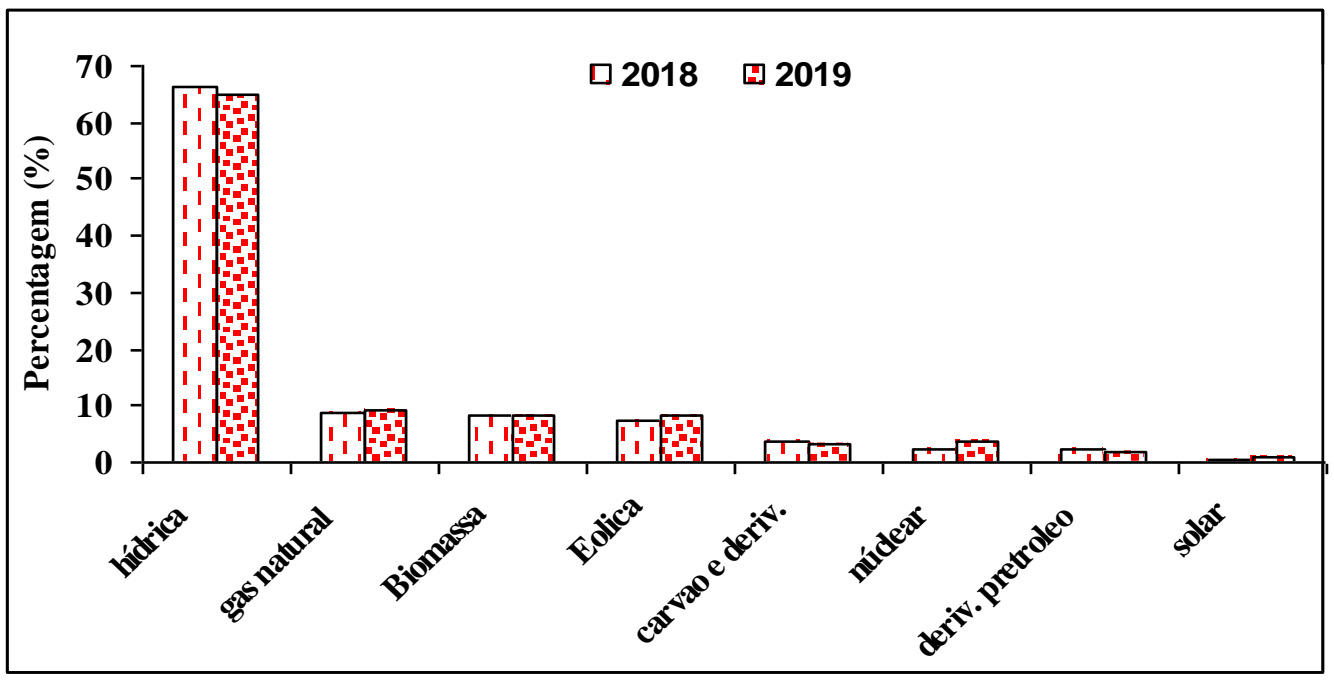

Fonte: dados da BEN (2020), elaborado pelo autor.

A evolução temporal por essa fonte hidráulica no Brasil, entre 2018 e 2019, mostra essa prioridade, cujos percentuais médios foram de $65,7 \%$, seguidos pelo gás natural $(9,0 \%)$, biomassa $(8,5 \%)$ e eólica $(8,0 \%)$. As outras fontes não renováveis: carvão e derivados, nuclear e derivados de petróleo, corresponderam com cerca de 9,0\% e uma inexpressiva quantidade de energia solar $(<$ de $1 \%)$.

Nesse enfoque, há cinco fontes alternativas de energia que se destacam na geração elétrica do Brasil: hídrica, biomassa, eólica, solar, gás natural, que somadas ultrapassam mais de $80 \%$ da produção nacional, cujos percentuais instalados são mostrados na Figura 4.

Figura 4. Matriz energética brasileira: potência instalada em operação, em \%.

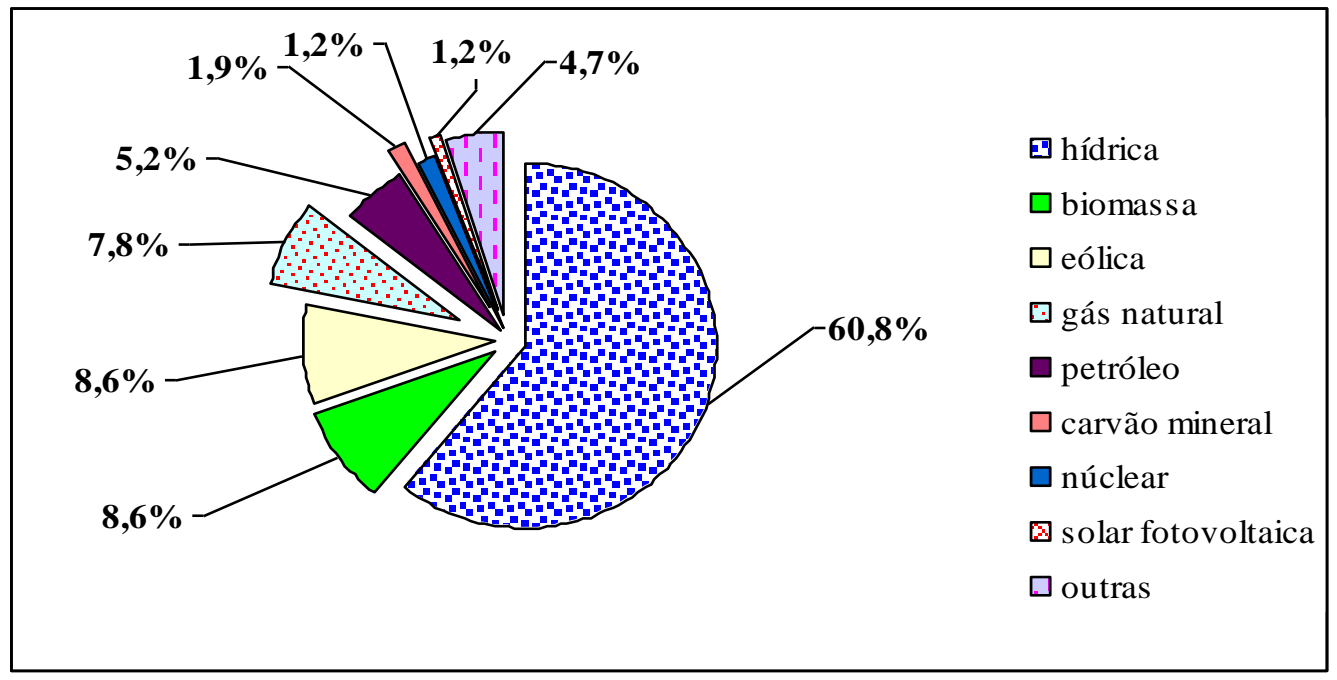

Fonte: ABSOLAR- http://www.absolar.org.br 
A energia solar é importante na preservação do meio ambiente, pois tem muitas vantagens sobre as outras formas de obtenção de energia, tais como: não ser poluente, não influir no efeito estufa, não precisar de turbinas ou geradores para a produção de energia elétrica.

O potencial de irradiância solar distribuído pelas diferentes regiões geográficas do Brasil é apresentado na Figura v 5.

Figura 5. Potencialidade da irradiância solar global por regiões geográficas

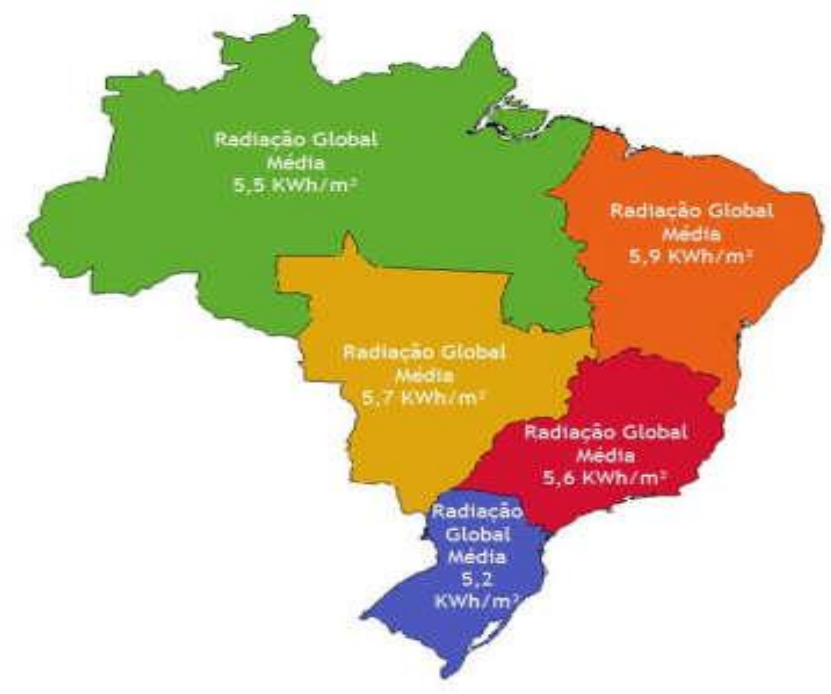

Fonte: INMET- https://portal.inmet.gov.br

O Brasil, além de ser um país privilegiado pela abundância de recursos hídricos é, também, em disponibilidade de irradiância solar. Duas fontes de energias renováveis, com prevalência para a primeira, embora fique na dependência do regime pluvial. Já, a segunda opção, tem baixo aproveitamento de conversão dessa energia disponível em energia elétrica.

Como mostra a Figura 5, há pouca variação espacial da irradiância solar global, quando se compara um recorte geográfico regional com outro, haja vista que os valores oscilam entre 5,2 na região sul e de $5,9 \mathrm{kw} \cdot \mathrm{m}^{-2} \cdot \mathrm{h}^{-1}$, no Nordeste.

A quantidade de energia solar no Nordeste do Brasil é abundante e sua conversão em energia elétrica pode e deve ser estimulada. Essa opção, certamente, poderá contribuir para poupar a água armazenada nos reservatórios das usinas hidroelétricas, permitindo o seu uso para fins de abastecimento público de água, que essa região tanto necessita.

As oscilações temporais da irradiância solar indicam que esse elemento do clima varia nas escalas espaciais e temporais, sendo influenciadas pelos fenômenos meteorológicos. Assim sendo, o principal condicionamento para as variações interanuais no Nordeste está ligado às mudanças permanentes nos padrões climáticos do planeta como: a elevação da temperatura global e pequenas irregularidades nos ciclos interanuais da Zona de Convergência Intertropical (ZCIT), por exemplo, ou por episódios de oscilações oceânicas e atmosféricas. 
A Figura 6 exemplifica as variações da irradiância solar global no trimestre mais chuvoso do Semiárido.

Figura 6. Médias diárias a irradiância solar global, para o trimestre mais chuvosooutono (mar-abr-mai).

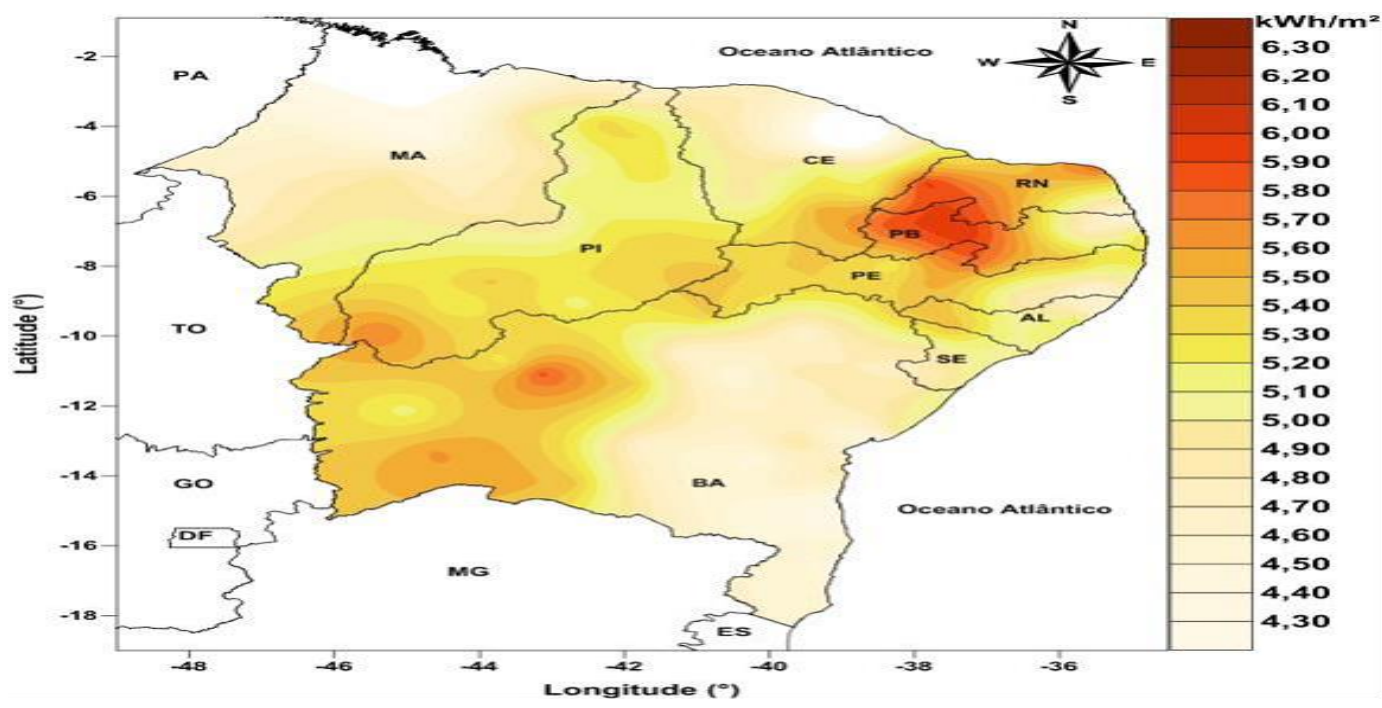

Fonte: Lima, 2015

Os meses de outono coincidem, com a estação chuvosa, na maioria das localidades do Semiárido nordestino. Mesmo que no período chuvoso coincida com maior nebulosidade, a disponibilidade média de energia solar, no Estado da Paraíba, varia entre 5,6 e 5,80 kWh. $\mathrm{m}^{-2}$.

Análises comparativas entre a irradiância solar global observada no nordeste do Brasil, nos meses de verão e inverno, são apresentadas nas Figuras 7 e 8.

Figura 7. Irradiância solar global no nordeste brasileiro nos meses de verão, no período: 2006/2016.

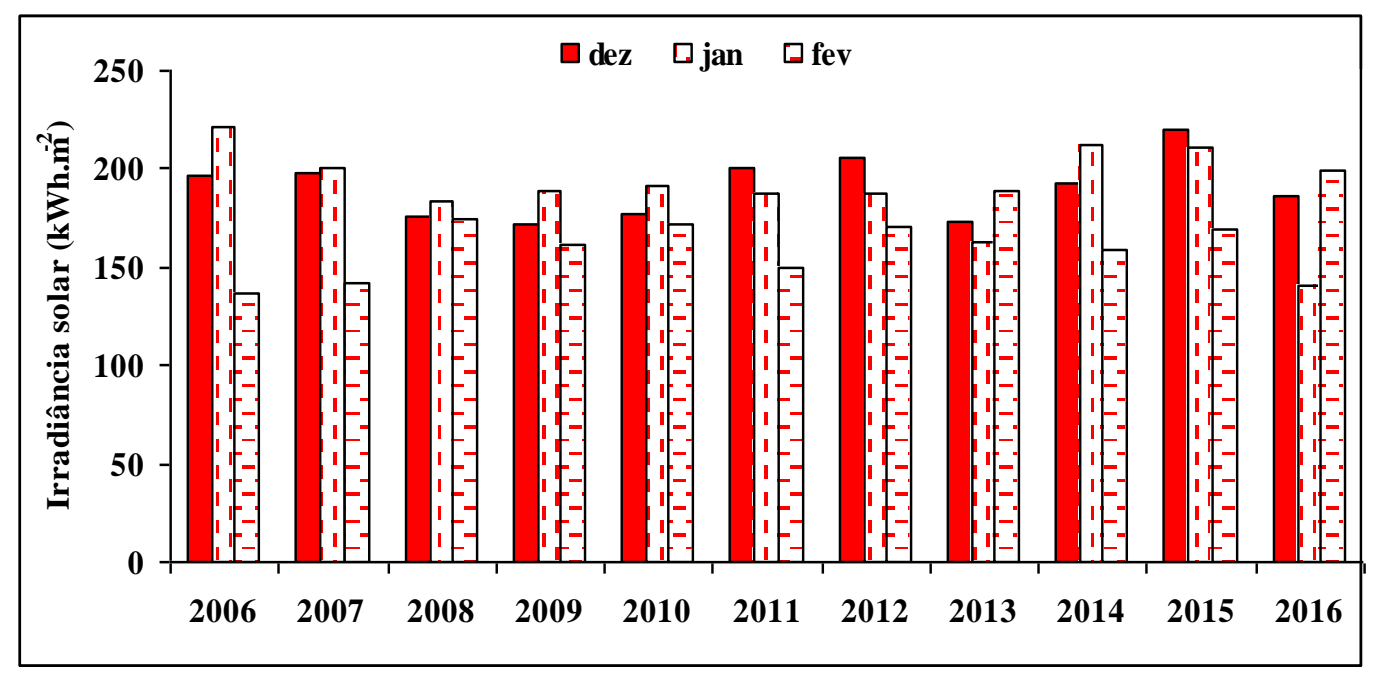

Fonte: EU SCIENCE HUB 2020 elaborado pelo autor 
Figura 8. Irradiância solar global no nordeste brasileiro nos meses de inverno. Médias do período: 2006/2016.

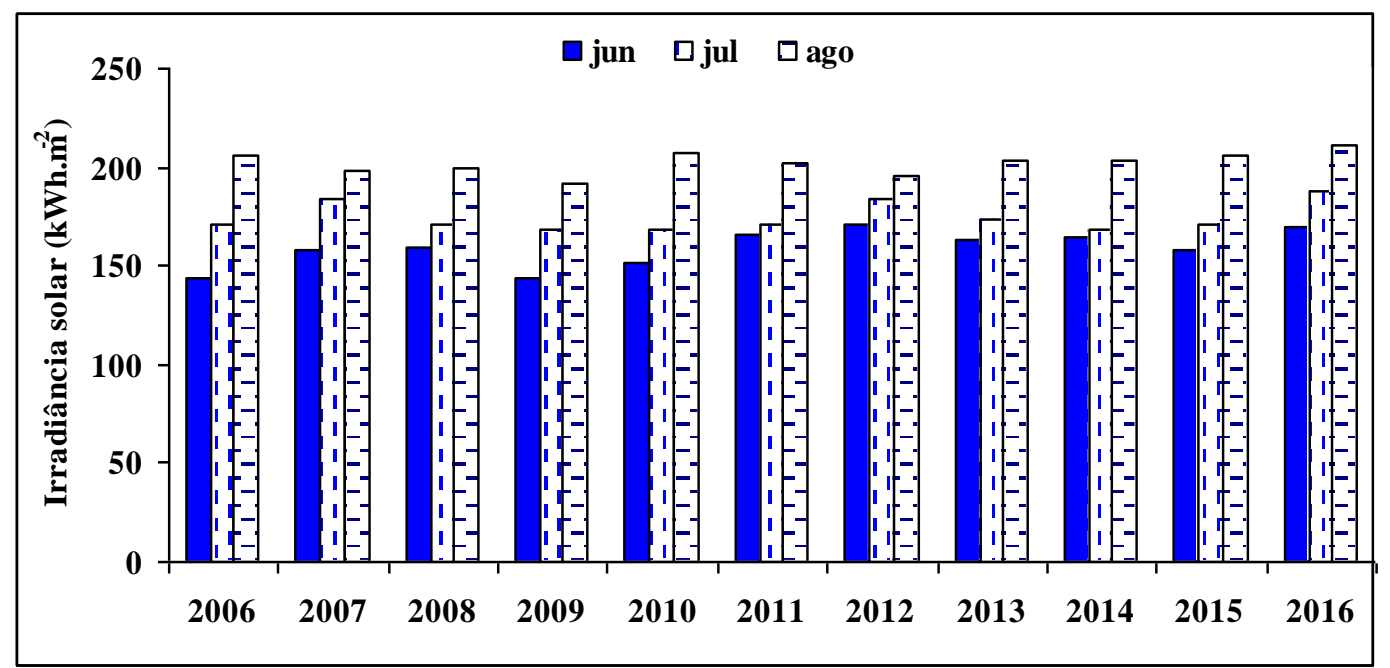

Fonte: EU SCIENCE HUB 2020 elaborado pelo autor

Ao comparar os quantitativos de irradiância solar no Nordeste, nos meses de verão com os de inverno, constata-se que há elevada disponibilidade independente do solstício. Comparando-se com os da Alemanha, os valores percentuais no Nordeste são superiores a 650 \% dos da Alemanha, o que desponta com maior potencial para conversão em energia elétrica.

De acordo com as projeções da Associação Brasileira de Energia Solar Fotovoltaica (ABSOLAR- http://www.absolar.org.br), o Brasil deve atingir 12,56 gigawatts (GW) de capacidade instalada de projetos de geração de energia solar fotovoltaica, em 2021, com um crescimento de $68 \%$ em relação à potência atual, de 7,46 GW.

A evolução da capacidade instalada para aproveitamento da irradiância solar global nos Estados da Paraíba, Pernambuco e no Rio Grande do Norte é apresentado na Figura 9.

Figura 9. Evolução da capacidade instalada para aproveitamento da irradiância solar global em energia elétrica em três Estados nordestinos.

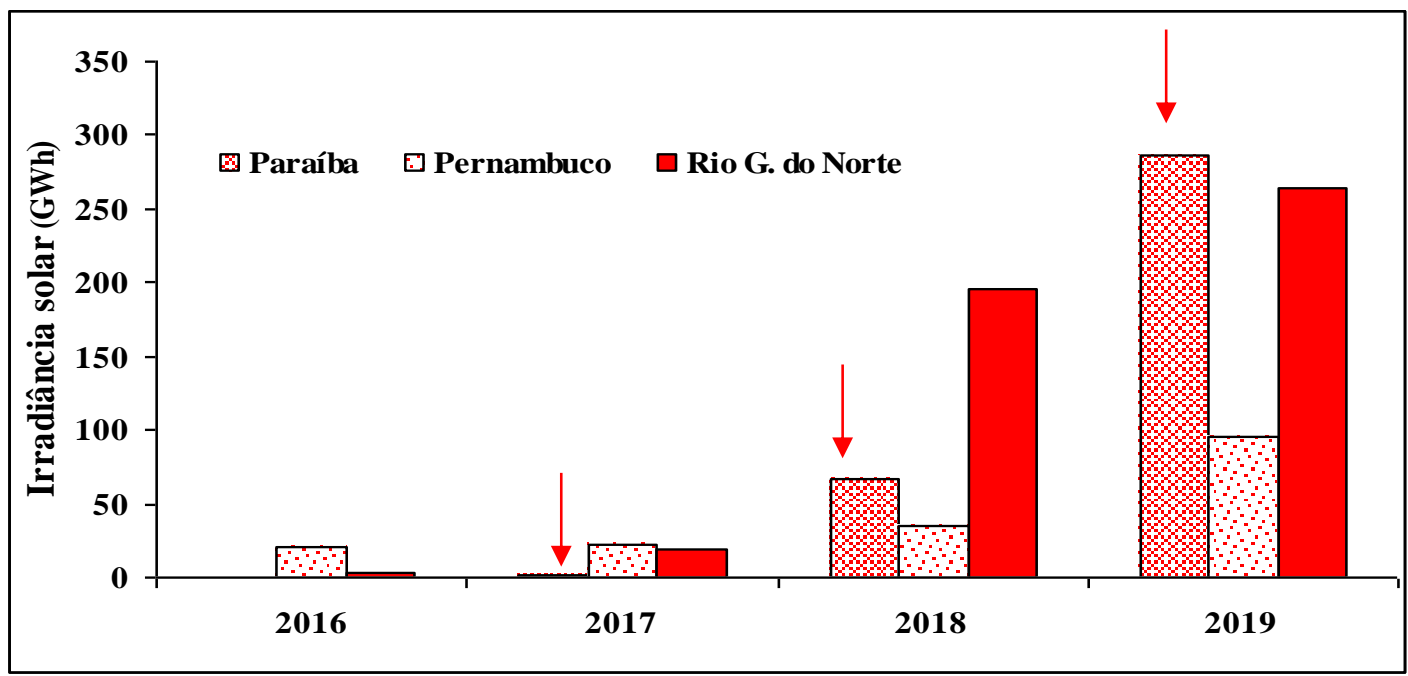

Fonte: dados da BEN, elaborado pelo autor. 
Nesses quatros anos, observa-se uma evolução crescente no aproveitamento da energia solar em elétrica. O Estado da Paraíba, por exemplo, vem apresentando o maior crescimento anual, a uma taxa média de 71,5, 65,2 e 18,7 GWh, respectivamente, da capacidade instalada, entre 2018 e 2019 , numa proporção de $325 \%$ ao ano.

Destaca-se, ainda, que a geração fotovoltaica diminui os níveis de poluição atmosférica e a emissão de gases do efeito estufa, além de contribuir na geração de emprego, o que concorda com Gasparin et al., (2021), que para cada megawatt instalado são gerados de 25 a 30 novos empregos, distribuídos entre instaladores, projetistas, fabricantes e montadores do sistema.

O Brasil mesmo tendo elevado potencial de irradiância solar, necessita investir em pesquisa das placas fotovoltaicas e na eficiência de conversão, a fim de adicionar uma matriz energética mais limpa e que não degrade o meio ambiente.

Concorda-se com a ANEEL (2008), que apesar do enorme potencial de energia solar no nordeste brasileiro, a capacidade instalada de geração solar fotovoltaica, inserida na geração da energia elétrica ainda é incipiente.

Projeções da Empresa de Pesquisa Energética (EPE, 2020) indicam cenários nos quais a energia solar pode atingir, até 2030 , cerca de $25 \mathrm{GW}$ de capacidade instalada, representando cerca de $10 \%$ da matriz de geração projetada para o mesmo ano.

A geração distribuída ganha força no Nordeste, através do Fundo Constitucional de Financiamento do Nordeste (FNE Sol), que inclui financiamento, também, para pessoas físicas. Com o apoio do Banco do Nordeste a geração de energia solar fotovoltaica tem crescido de forma expressiva, tanto na geração distribuída quanto na centralizada, cujos valores de potência instalada, em MW, e em percentagem são apresentados na Figura 10, para os cinco Estados.

Figura 10. Ranking dos cinco Estados do NE, com capacidade instalada do sistema solar fotovoltaico.

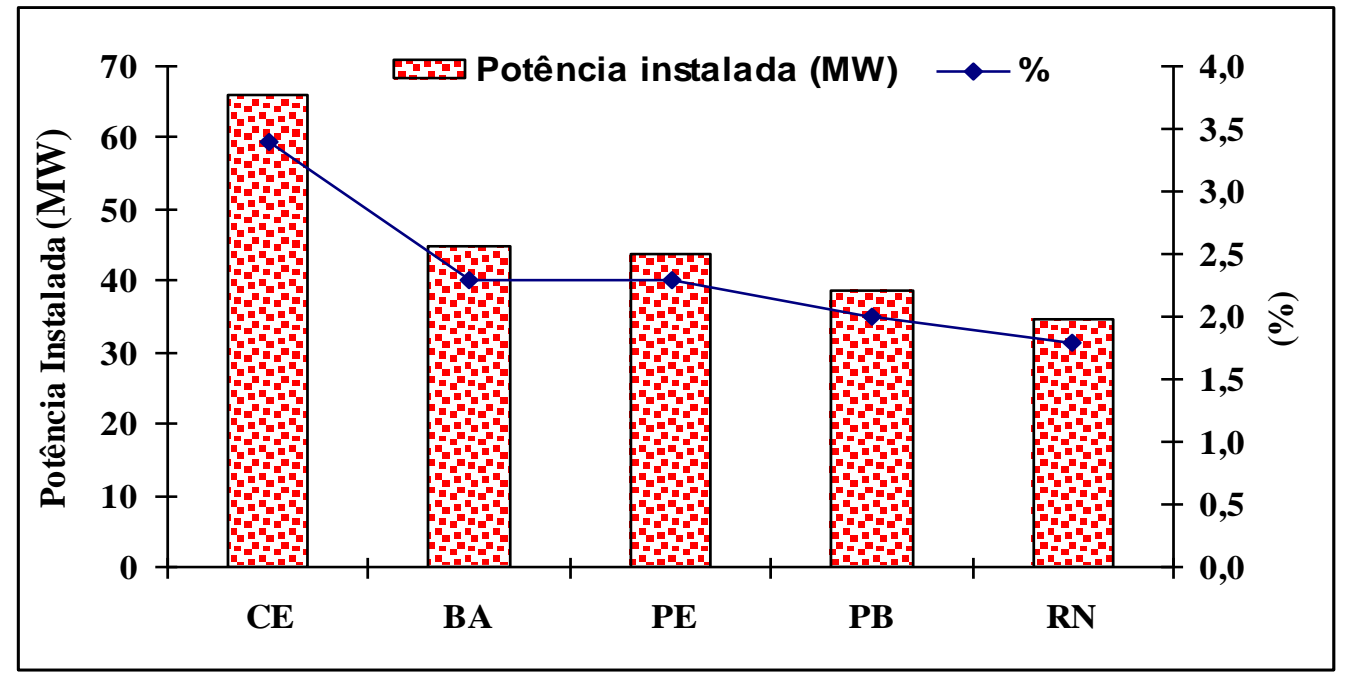

Fonte: https://elektsolar.com.br/infografico-da-absolar, 2020- elaborado pelo autor 
Os potenciais de energia solar no Brasil e no NE, em especial, viabilizam as suas aplicabilidades mesmo em locais isolados, encontrados em qualquer recorte geográfico, porque há disponibilidade de irradiância solar, quando comparado com outras fontes de energia.

As perspectivas são ainda mais animadoras, haja vista a redução de cerca de $80 \%$ dos custos de produção dos sistemas fotovoltaicos, no último decênio, como mostra o relatório da IRENA (2021), em virtude da inovação tecnológica, que resultou num aumento de $30 \%$ na eficiência dos painéis solares e mais de $20 \%$ na produtividade em relação aos valores atuais.

A redução de custo projetada para o sistema $\mathrm{FV}$, associado ao elevado potencial de irradiação solar no Nordeste e aos incentivos governamentais e da iniciativa privada, vêm incentivando o crescimento de projetos de usinas fotovoltaicas na região, cuja trajetória de redução de custo é apresentada na Figura 11.

Figura 11. Involução anual de custo para sistemas FV residencial e comercial no Brasil.

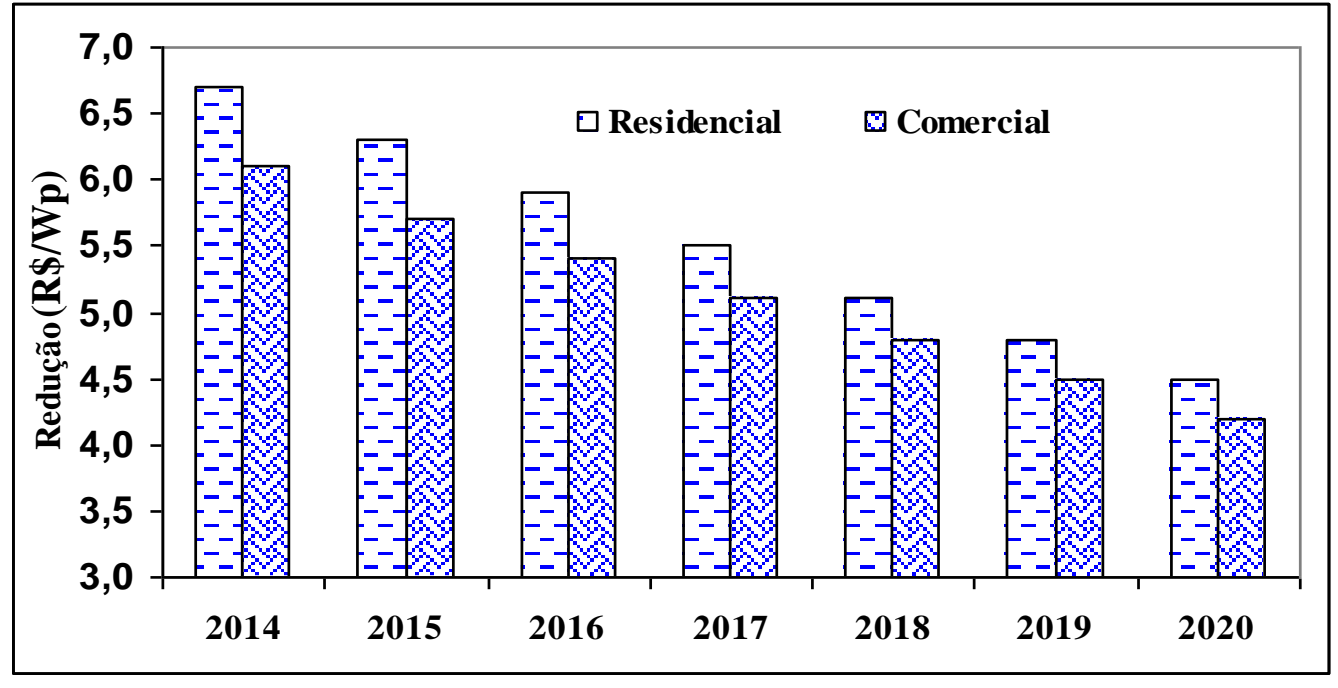

Fonte: Dados da Empresa de Pesquisa Energética (EPE, 2019 e 2020), elaborado pelos autores

Como pode ser observado na Figura 11, o custo médio para instalação do sistema fotovoltaico vem caindo gradativamente tanto para as unidades residenciais quanto para as comerciais. Dados da Agência Nacional de Energia Elétrica, o número de micro e mini unidades geradoras de energia solar passou de 4,3 mil, em 2019, para mais de 10 mil em 2020, ou seja, um crescimento de $130,8 \%$.

É importante destacar, que alguns fatores contribuem para o crescimento do uso da tecnologia fotovoltaica no nordeste brasileiro, tais como: redução de preços de equipamentos, aumento na eficiência das placas solares e, especialmente, a elevada disponibilidade e regularidade da irradiância solar radiação ao longo do ano.

A uniformidade da irradiância solar é a maior certeza na performance e viabilidade financeira de uma usina fotovoltaica. Essa é a razão que explica a necessidade de se estabelecer os indicadores do regime de irradiância local. 


\section{CONCLUSÕES}

O Brasil é um dos países que mais utiliza energia de fontes renováveis, especialmente, a hídrica. No entanto, essa fonte causa impacto ambiental com a construção de hidroelétricas e com o alagamento de terras férteis, além da dependência do regime pluvial.

A elevada disponibilidade e regularidade da irradiância solar no Semiárido nordestino, durante os meses do ano, justificam-se a escolha da fonte fotovoltaica, tanto por não degradar o meio ambiente quanto pela redução nos custos de instalação.

A energia fotovoltaica é uma fonte promissora para complementar a matriz energética nacional, embora haja necessidade de avanços tecnológicos para aumentar a eficiência de conversão de painéis fotovoltaicos, a fim de tornar essa fonte mais competitiva.

O Estado da Paraíba tem apresentado maior evolução temporal no crescimento da capacidade instalada do sistema fotovoltaico, que os Estados de Pernambuco e Rio Grande do Norte.

O potencial de energia solar no nordeste brasileiro mostra ser uma alternativa viável e um passo fundamental para atingir um padrão de desenvolvimento sustentável, contribuindo-se, também, na geração de emprego e renda.

O Brasil sendo detentor de um potencial gigantesco de irradiância solar há necessidade de investir na pesquisa tecnológica de aproveitamento e eficiência de conversão, a fim de adicionar uma matriz energética mais limpa e que não degrade o meio ambiente

\section{REFERÊNCIAS}

ABBUD, O. A; TANCREDI, M. Transformações recentes da matriz brasileira de geração de energia elétrica. Textos para Discussão n. 69. Brasília: Centro de Estudo da Consultoria do Senado Federal, 64 p, 2010. Disponível: http://www.senado.gov.br/conleg/

AGÊNCIA NACIONAL DE ENERGIA ELÉTRICA (ANEEL). Atlas de energia elétrica do Brasil / Agência Nacional de Energia Elétrica. Brasília: ANEEL, 2008, 3ª edição, 236 p, 2008.

AGÊNCIA NACIONAL DE ENERGIA ELÉTRICA (ANEEL). Nota Técnica n. 0056/2017SRD/ANEEL. 2017. Atualização das projeções de consumidores residenciais e comerciais com microgeração solar fotovoltaicos no horizonte 2017-2024. 26p, 2017

ALMEIDA, H. A. Climatologia aplicada à geografia [Livro eletrônico]. Campina Grande: EDUEPB, 2016.317p

BALANÇO ENERGÉTICO NACIONAL 2020 (BEN). Ministério de Minas e Energia (MME). Empresa de Pesquisa Energética (EPE). In: Rio de Janeiro, RJ. Relatório Síntese/Ano Base 2019, 73 p, 2020. 
BARBOSA, R. R., PINHEIRO, R., DANIELLE B. M. DELGADO, D. B. M. Energia solar fotovoltaica no semiárido: potencial, cenário atual e perspectivas. In: II Congresso Internacional da Diversidade do Semiárido, Campina Grande, PB. Julho de 2017, Anais, CD-R, 11 pp.

BRITO, M. A. G., SAMPAIO, L. P.; JUNIOR, L. G.; CANESIN, C. A. Research on photovoltaics: review, trends and perspectives. In: Brazilian Power Electronics Conference (COBEP). p. 531-537, 2011

DIENSTMANN, G. Energia solar: Uma Comparação de Tecnologias. In: Universidade Federal do Rio Grande do Sul, Departamento de Engenharia Elétrica, Porto Alegre, 2009, 92 fls.

EMPRESA DE PESQUISA ENERGÉTICA (EPE). Anuário Estatístico de Energia Elétrica 2021, ano base 2020, 256p. Fonte: https://www.epe.gov.br/sites-pt/publicacoes-dados-abertos/ publicacoes/PublicacoesArquivos/publicacao-160/acesso 22.01.2022.

EMPRESA DE PESQUISA ENERGÉTICA (EPE). Balanço Energético Nacional 2019: Ano base 2018. Relatório Síntese. Rio de Janeiro: EPE, 2019, 67p. Fonte: https://www.epe.gov.br/ sites-pt/publicacoes-dados-abertos/publicacoes/PublicacoesArquivos/publicação. Acesso 22.01.2022.

GASPARIN, F. B., LIMA, V. O. D.; MICHELETTI, D. H.; BURINA, E. L. K. A Influência de Políticas Públicas para o Progresso da Geração Solar Fotovoltaica e Diversificação da Matriz Energética Brasileira. Rev. Virtual Quim., p. 1-5, 2021.

GOLDEMBERG, J.; LUCON, O. Energias renováveis: um futuro sustentável. Revista USP, São Paulo, n.72, p. 6-15, 2007.

INSTITUTO BRASILEIRO DE GEOGRAFIA E ESTÁTISTICA (IBGE). População. IBGE, 2020. Disponível em: <https://cidades.ibge.gov.br/brasil/pb/panorama. Acesso em: 13 out 2020.

INTERNATIONAL RENEWABLE ENERGY AGENCY (IRENA). Abu Dhabi: Irena, 2021. Disponível em: https://www.irena.org/Publications, em 16.02.2021.

LIMA, F. J. L. D. Previsão de irradiação solar no nordeste do Brasil empregando o modelo wrf ajustado por redes neurais artificiais (RNAs). INPE. São José dos Campos, p. 37. 2015.

MARTINS, F. R.;, PEREIRA, E. B. , ABREU, S. L. Satellite-derived solar resource maps for Brazil under SWERA project. Solar Energy, v. 81 p. 517-528, 2007.

MOREIRA JÚNIOR, O.; SOUZA, C. C. Aproveitamento fotovoltaico, análise comparativa entre Brasil e Alemanha. INTERAÇÕES, v. 21, n. 2, p. 379-387, 2020.

ROMEIRO, A. R. Desenvolvimento sustentável: uma perspectiva econômico-ecológica. Estudos Avançados, v. 26, n.74, p. 65-92, 2012

SANZIO, E. A., NASCIMENTO, M. R. D. Desenvolvimento de um equipamento suporte móvel para módulos fotovoltaicos otimizados energia solar. CENTRO FEDERAL DE EDUCAÇÃO TECNOLÓGICA CELSO SUCKOW DA FONSECA - CEFET/RJ. Rio de Janeiro. 2016.

SILVA, G. L.; OLIVEIRA, M. S.; SILVA, R. M.; SILVA, N. L. Análise de viabilidade econômica entre o uso de energia em grid e a solar no sertão paraibano. Energ. Agric., Botucatu, v. 31, n.1, p.89-96, 2016. 
SIMIONI, T. O Impacto Da Temperatura Para O Aproveitamento Do Potencial Solar Fotovoltaico Do Brasil. Dissertação (Mestrado Planejamento Energético), Rio de Janeiro. p. 160-167, 2017.

SUZIGAN, K. R. A transição para uma matriz energética limpa: os avanços na tecnologia solar. 2015. Dissertação (mestrado) - Universidade Estadual de Campinas, Campinas, SP, 121p, 2015.

VERMA, D.; MIDTGARD, O.-M.; SATRE, T. O. Review of photovoltaic status in a European (EU) perspective. In: 37th IEEE Photovoltaic Specialists Conference (PVSC). p. 3292-3297, 2011.

Recebido em: 05/01/2022

Aprovado em: 08/02/2022

Publicado em: 11/02/2022 